\title{
The alignment technique of inter-territorial differences in housing and municipal development of urban agglomeration
}

\author{
$A$ Stupina $^{1,2,3,{ }^{*}}, R$ Kuzmich $^{1}, I$ Rouiga $^{1}$, and $A$ Yamshchikov $^{1}$ \\ ${ }^{1}$ Siberian Federal University, 79 Svobodny pr., Krasnoyarsk 660041, Russia \\ ${ }^{2}$ Siberian State University of Science and Technologies, Krasnoyarsky Rabochy Av., Krasnoyarsk 660037, Russia \\ ${ }^{3}$ Krasnoyarsk State Agrarian University, Mira Av., Krasnoyarsk 660049, Russia
}

\begin{abstract}
The article presents the stages of the alignment technique of inter-territorial differences in the housing and municipal development of the urban agglomeration. Approbation of the technique was implemented within the framework of private purposes (alignment of the population's security in housing and municipal services and alignment of the state system of the city economy) using the example of the Krasnoyarsk agglomeration.
\end{abstract}

\section{Introduction}

At the moment, the evolution of scientific views has led to the perception of urban agglomeration as a progressive and integral form of settlement, which concentrates a significant economic potential (Lappo and Lyubovnyi, 2011; Selivanova, 2007). As a result of the discussions, most scientists agreed that urban agglomeration is a compact and relatively developed set of complementary urban and rural settlements clustered around one or several huge cities and united by intensive multifaceted connections into a complex and dynamic unity; this is the space of potential and real interactions, which incorporates the weekly life cycle of the majority of inhabitants of a modern large city and its satellite zone (Kuznetsova, 2009). This type of settlement allows combining the benefits of concentration of various services in large cities with a dispersed nature of their realization and consumption, thus, maintaining a dynamic balance between the diverse economic, social and environmental conditions of people's life (McCann and Folta, 2011).

Sharp inter-territorial differences in the housing and municipal development of the urban agglomeration have as their inevitable consequence the expansion of the number of lagging territories, the weakening of the mechanisms of inter-territorial interaction and the growing contradictions, which makes it very difficult to implement a unified policy of housing and municipal transformation (Quigley and Rosenthal, 2005). It is proposed to use method to eliminate these negative consequences and to align inter-territorial differences in the housing and municipal development of the urban agglomeration allowing:

-choose indicators affecting on inter-territorial differences in the housing and municipal development on the basis of objects and purposes harmonization of aligning inter-territorial differences in the housing and municipal development of urban agglomeration; -comprehensively assess the variation and identify trends in housing and municipal development of municipalities with the help of a developed system of selected indicators and assessment methods that characterize the degree of inter-territorial differences; make management decisions about the need to reduce it;

-choose tools that require levels alignment of their housing and municipal development in the urban agglomeration depending on the capabilities and needs of municipalities;

-develop a set of measures aimed at aligning interterritorial differences in the housing and municipal development of urban agglomeration using the selected tools.

\section{Methods}

The proposed technique for alignment inter-territorial differences in the housing and municipal development of the urban agglomeration consists of seven stages. The first stage of the technique is the harmonization of management objects and purposes for alignment of interterritorial differences in the housing and municipal development of the urban agglomeration. Municipal and housing facilities are considered as objects of managing influence, i.e. the authorities' attention is directed on it to align of inter-territorial differences in the housing and municipal development of the agglomeration (Borovaya and Gubanova, 2008).

Since the alignment of inter-territorial differences in the housing and municipal development of the urban agglomeration is a multi-purpose system, it is necessary to clearly identify the purposes of alignment and distribute them on three levels (Klistorin, 2006): strategic, tactical and operational.

\footnotetext{
* Corresponding author: $\underline{\mathrm{h} 677 \mathrm{hm} @ \text { gmail.com }}$
} 
Table 1. Indicator "Coefficient of housing and municipal service provision" before and after the measure.

\begin{tabular}{|c|c|c|c|c|c|c|}
\hline Municipalities & $\mathbf{2 0 1 4}$ & $\mathbf{2 0 1 5}$ & $\mathbf{2 0 1 6}$ & $\mathbf{2 0 1 7}$ & $\mathbf{2 0 1 8}$ & $\begin{array}{c}\text { Measure } \\
\text { implementation }\end{array}$ \\
\hline \multicolumn{7}{|c|}{ Coefficient of housing and municipal service provision, \% } \\
\hline Krasnoyarsk & 79.13 & 79.49 & 79.57 & 79.71 & 80.17 & 80.48 \\
\hline Divnogorsk & 72.14 & 72.14 & 72.46 & 78.83 & 79.11 & 79.44 \\
\hline Sosnovoborsk & 85.71 & 85.71 & 85.71 & 85.71 & 85.71 & 85.93 \\
\hline Emelyanovskiy district & 30.90 & 34.66 & 25.96 & 25.73 & 25.97 & 27.11 \\
\hline Suhobuzimsky district & 31.14 & 34.44 & 30.84 & 30.99 & 30.93 & 32.00 \\
\hline Berezovsky district & 48.07 & 48.20 & 48.33 & 49.87 & 51.26 & 52.01 \\
\hline Mansky district & 19.78 & 20.57 & 24.31 & 19.73 & 19.91 & 21.15 \\
\hline Integral indicator & 52.41 & 53.60 & 52.46 & 52.94 & 53.30 & 54.02 \\
\hline
\end{tabular}

A set of purposes of different levels should be represented by a tree of purposes. Advantages of the tree of purposes are that it allows building relationships between the purposes of different levels, to split large purposes into stages, to see a clear picture of the system of purposes. A tree of purposes connects long-term and short-term purposes, purposes from different areas of life. The use of this technique makes it possible to create a strategic picture for alignment of inter-territorial differences in the housing and municipal development of the urban agglomeration. The top level of the tree of purposes can be a mission or vision (Kuznetsova, 2009).

The structure of the purpose system should correspond to the structure of the control object, then each purpose is achieved by a certain element of this object (Khokhlova, 2008). In this case, the purposeoriented measure of each element of the control object is increased. Perhaps it is necessary to change the structure of the control object to achieve the required matching.

In accordance with the principle of measurability, inherent in the purposes for alignment of inter-territorial differences in the housing and municipal development of the urban agglomeration, a need of for their transformation into specific tasks (Skufyina and Baranov, 2007). For the purposeful alignment of interterritorial differences in the urban agglomeration and its orientation to specific final results, at the second stage of the proposed technique, particular indicators of the assessment of the level of inter-territorial differences in housing and municipal development of municipalities in the urban agglomeration are selected, thus an integral indicator is constructed. The particular indicators are transformed and aggregated to compare them with each other (Amirova, 2018). At the same time, the level of inter-territorial differences in the housing and municipal development of the urban agglomeration can be assessed in the third stage of the technique by comparing the achieved results using the proposed measurement methods: the range of variation, the average square deviation and the coefficient of variation (Kuzmich et al., 2017). This set of methods considers all factors, conditions and features of housing and municipal development of municipalities in the urban agglomeration.

The harmonization of objects and purposes, the choice of indicators for assessing the level of interterritorial differences in the housing and municipal development of municipalities in the urban agglomeration, as well as methods for measuring interterritorial differences provide the possibility of managing results, creation the system of motivation, comparison and assessment of options for solutions and, finally, the forces concentration in priority directions of activity, the formation of conditions that ensure the required results, as well as the work organization of the management subjects to achieve the set purposes (Kalinnikova, 2009).

If on the fourth stage of the technique, as a result of the verification, the need to reduce inter-territorial differences in the housing and municipal development of the urban agglomeration does not occur, then the management object and purpose are refined, and then the level and measure of the degree of inter-territorial differences in the housing and municipal development of municipalities is assessed again.

In the fifth stage, the alignment direction is selected depending on the third stage of this technique. In what direction of housing and municipal development (housing provision, the cost of housing, provision of housing and municipal services, the provision quality of housing and municipal services, sanitary cleaning system), according to the assessment of inter-territorial differences in the urban agglomeration, "bottle necks" appear, so such "necks" need in development of measures for alignment, relying on existing alignment tools (Klevtsova et. al., 2018).

In accordance with the purposes for alignment of inter-territorial differences in housing and municipal development, in the sixth stage, alignment tools of the level of inter-territorial differences in the housing and municipal development of the urban agglomeration are chosen. At the seventh stage of the technique, practical measures for alignment of inter-territorial differences in the housing and municipal development of the urban agglomeration are taken with the help of selected tools.

\section{Results}

Let's consider approbation of method within the framework of particular purposes (alignment of the provision of housing and municipal services and alignment of the state of city economy system) on the example of the Krasnoyarsk agglomeration. Construction and commissioning of an incineration plant is measure for aligning inter-territorial differences in the housing 
Table 2. Indicator "The degree of recycling" before and after the measure.

\begin{tabular}{|c|c|c|c|c|c|c|}
\hline Municipalities & $\mathbf{2 0 1 4}$ & $\mathbf{2 0 1 5}$ & $\mathbf{2 0 1 6}$ & $\mathbf{2 0 1 7}$ & $\mathbf{2 0 1 8}$ & $\begin{array}{c}\text { Measure } \\
\text { implementation }\end{array}$ \\
\hline \multicolumn{7}{|c|}{ The degree of recycling, \% } \\
\hline Krasnoyarsk & 90.00 & 93.00 & 95.00 & 96.00 & 97.00 & 98.29 \\
\hline Divnogorsk & 28.00 & 30.00 & 52.00 & 58.00 & 62.00 & 78.44 \\
\hline Sosnovoborsk & 38.00 & 42.00 & 60.00 & 75.00 & 80.00 & 88.65 \\
\hline Emelyanovskiy district & 87.00 & 88.00 & 90.00 & 92.00 & 93.00 & 96.03 \\
\hline Suhobuzimsky district & 3.00 & 5.00 & 7.000 & 9.00 & 10.00 & 48.94 \\
\hline Berezovsky district & 85.00 & 86.00 & 87.00 & 89.00 & 90.00 & 94.33 \\
\hline Mansky district & 2.00 & 3.00 & 5.00 & 7.00 & 8.00 & 49.50 \\
\hline Integral indicator & 47.57 & 49.57 & 56.57 & 60.86 & 62.86 & 79.17 \\
\hline
\end{tabular}

and municipal development of urban agglomeration (Anikina and Kuzmich, 2010). The plant's productivity is 360 thousand tons per year, that is, one thousand tons per day. The name "incineration plant" does not accurately and fully determine the importance of the enterprise; rather it is a small heat and power plant with alternative fuel. The enterprise produces about $10 \mathrm{MWh}$ of electricity.

As a result of the measure implementation, two indicators will be changed, assessing assess the level of housing and municipal development of the Krasnoyarsk agglomeration: "Coefficient of housing and municipal service provision" (Table 1) and "The degree of recycling" (Table 2 ).

Thus, according to Table 1, the indicator "Coefficient of housing and municipal service provision" increased in relation to the values of this indicator in 2018 by $0.72 \%$. According to Table 2, the indicator "The degree of recycling" increased in comparison with the value in 2018 by $16.31 \%$. An increase in these indicators indicates a positive effect of the measure taken for the Krasnoyarsk agglomeration as a whole.

The implementation of projects on the construction of incineration plants using existing agglomeration effects and the orientation of housing and municipal development programs for the integrated use of economic potential and innovative development will generally improve the level of territories development, and thereby reduce the degree of inter-territorial differences in the housing and municipal development of the Krasnoyarsk agglomeration.

It should be noted, that such agglomeration economy, which appears as a result of interaction within the framework of the construction and commissioning of the incineration plant, applies to all municipalities located in the Krasnoyarsk agglomeration. As a result, we note a decrease, in particular, in the indicator "The degree of recycling" an absolute and average deviations in the degree of inter-territorial differences by 39.64 and 15.81 units respectively, the degree of its volatility by $31.66 \%$; also we note a decrease in the indicator "Coefficient of housing and municipal service provision" an absolute and average values of deviations in the degree of interterritorial differences by 1.02 and 0.4 units respectively, the degree of its variability by $1.4 \%$ (Table 3 ).

\section{Conclusion}

According to the obtained results (Table 3), the measure taken to align inter-territorial differences in the housing and municipal development of the Krasnoyarsk agglomeration proved to be effective, i.e. reduced their degree.

Such agglomeration economy, which appears as a result of interaction within the framework of the proposed measure, applies to all municipalities located in the Krasnoyarsk agglomeration within a radius of $30 \mathrm{~km}$ (Lavrovsky, 2009). Such economy is obtained due to economy of production scale and economy localization associated with the location of enterprises.

Having new assessments of inter-territorial differences in the housing and municipal development of the Krasnoyarsk agglomeration, the implementation of new measures can be planned by changing the choice of the alignment direction in the housing and municipal

Table 3. The degree of inter-territorial differences in the housing and municipal development of Krasnoyarsk agglomeration implementing measure.

\begin{tabular}{|c|c|c|c|c|c|c|}
\hline \multirow[b]{2}{*}{ Assessing indicators } & \multicolumn{3}{|c|}{$\begin{array}{c}\text { The degree of inter-territorial differences } \\
\text { before the measure }\end{array}$} & \multicolumn{3}{|c|}{$\begin{array}{c}\text { The degree of inter-territorial differences after } \\
\text { the measure }\end{array}$} \\
\hline & $\begin{array}{c}\text { The range } \\
\text { of variation, } \\
R \text {, units }\end{array}$ & $\begin{array}{c}\text { The average } \\
\text { square } \\
\text { deviation, } \sigma, \\
\text { units }\end{array}$ & $\begin{array}{c}\text { The } \\
\text { coefficient } \\
\text { of variation, } \\
V_{\sigma}, \% \\
\end{array}$ & $\begin{array}{c}\text { The range } \\
\text { of variation, } \\
R \text {, units }\end{array}$ & $\begin{array}{l}\text { The average } \\
\text { square } \\
\text { deviation, } \sigma, \\
\text { units }\end{array}$ & $\begin{array}{c}\text { The } \\
\text { coefficient of } \\
\text { variation, } V_{\sigma}, \\
\% \\
\end{array}$ \\
\hline $\begin{array}{l}\text { Coefficient of housing } \\
\text { and municipal service } \\
\text { provision }\end{array}$ & 65.80 & 26.20 & 49.16 & 64.78 & 25,80 & 47.76 \\
\hline The degree of recycling & 89.00 & 35.68 & 56.76 & 49.36 & 19.87 & 25.10 \\
\hline
\end{tabular}


development of the agglomeration.

Thus, developed technique for alignment of interterritorial differences in housing and municipal development of Krasnoyarsk agglomeration has an iterative character and is intended for constant control over the degree of indicators characterizing interterritorial differences in the housing and municipal development of agglomeration.

\section{References}

[1] E.A. Amirova, Methodology for assessing the differentiation of socio-economic development on the basis of a single indicator, Issues of structuring the economy, 4, 25-27 (2018).

[2] Yu.A. Anikina, R.I. Kuzmich, Smoothing the differentiation of socio-economic development of municipalities in the urban agglomeration, Vestnik of the Siberian State Aerospace University named after ac. M.F. Reshetnev, 28, 183-188 (2010).

[3] S.L. Borovaya, Methodology for assessing the differentiation of the socio-economic development of the region, Journal of "Regionology", 1, 77-85 (2008).

[4] I.O. Kalinnikova, Management of social and economic potential of the region, St. Petersburg Peter (2009).

[5] O. Khokhlova, Regional Diagnostics as a Methodological Base for Statistical Study of the Regional Economy, Problems of Statistics, 9, 2234 (2008).

[6] M.G. Klevtsova, Yu.S. Polozhentseva, A.R. Stepanova, Institutional Tools for Overcoming the Differentiation of the Economic Space in the Context of Globalization, Innovative Economy: Prospects for Development and Improvement, 8, 34, 148-155 (2018).

[7] V. Klistorin, Quality of economic growth and regional development, Region: economy and sociology, 3, 25-44 (2006).

[8] R. Kuzmich, I. Bagdasarian, A. Stupina, E. Antosik, S. Ezhemanskaya, Selection of indicators and methods of estimation of the degree of inter-territorial differences in housing and municipal development of urban agglomeration, 4th International Multidisciplinary Scientific Conference on Social Sciences and Arts SGEM 2017, Sofia: STEF92 Technology Ltd, 823-830 (2017).

[9] O.V. Kuznetsova, Economic development of regions: Theoretical and practical aspects of state regulation, Moscow: The book house "LIBROKOM" (2009).

[10] G.M. Lappo, V.Y. Lyubovnyi, Largest urban agglomerations in Russia at the beginning of the 21 st century: status, problems, and approaches to solving them, Regional research of Russia, 1, 2, 133-40 (2011).
[11] B. Lavrovsky, Measurement of regional asymmetry on the example of Russia, Journal of "Questions of Economics", 3, 42-52 (2009).

[12] B.T. McCann, T.B. Folta, Performance differentials within geographic clusters, Journal of Business Venturing, 26, 104-123 (2011).

[13] J.M. Quigley, L.A. Rosenthal, The Effects of Land Use Regulation on the Price of Housing: What Do We Know? What Can We Learn?, Cityscape, 8, 69-138 (2005).

[14] T. Selivanova, Agglomerations of Russia in the XXI century, Journal of "Bulletin of the Regional Development Fund of the Irkutsk Region", 1 (2007).

[15] T.P. Skufyina, S.V. Baranov, Analysis and regulation of the development of regional socioeconomic systems (using the example of the North of Russia), Apatity: KSC RAS (2007). 